\title{
Calorie restriction minimizes activation of insulin signaling in response to glucose: potential involvement of the growth hormone-insulin-like growth factor 1 axis
}

Hiroko Hayashi ${ }^{1}$, Haruyoshi Yamaza ${ }^{1}$, Toshimitsu Komatsu ${ }^{1}$, Seongjoon Park ${ }^{1}$, Takuya Chiba 1, Yoshikazu Higami ${ }^{1}$, Takeshi Nagayasu ${ }^{2}$, Isao Shimokawa ${ }^{1}$, *

${ }^{1}$ Department of Investigative Pathology, Unit of Basic Medical Sciences, Nagasaki University Graduate School of Biomedical Sciences

${ }^{2}$ Department of Surgical Oncology, Unit of Translational Medical Sciences, Nagasaki University Graduate School of Biomedical Sciences

* Correspondence to: Isao Shimokawa, Department of Investigative Pathology, Unit of Basic Medical Sciences, Nagasaki University Graduate School of Biomedical Sciences, 12-4 Sakamoto 1-Chome, Nagasaki City, Nagasaki, 852-8523, Japan

E-mail: shimo@nagasaki-u.ac.jp

Tel.: +81-95-819-7050

Fax: +81-95-819-7052

Keywords: calorie restriction; growth hormone-insulin-like growth factor 1 axis; insulin signaling; glucose metabolism; Akt; FoxO1 


\begin{abstract}
Calorie restriction (CR) may modulate insulin signaling in response to energy intake through suppression of the growth hormone (GH)-IGF-1 axis. We investigated the glucose-stimulated serum insulin response and subsequent alterations in insulin receptor (IR), Akt, and FoxO1 in the rat liver and quadriceps femoris muscle (QFM). Nine-month-old wild type (W) male Wistar rats fed ad libitum (AL) or a 30\% CR diet initiated at 6 weeks of age and GH-suppressed transgenic (Tg) rats fed AL were killed 15 min after intraperitoneal injection of glucose or saline. In W-AL rats, the serum insulin concentration was elevated by glucose injection. Concomitantly, the phosphorylated (p)-IR and p-Akt levels were increased in both tissues. The active FoxO1 level was decreased in the liver, but not significantly in the QFM. In $\mathrm{W}-\mathrm{CR}$ and $\mathrm{Tg}-\mathrm{AL}$ rats, the serum insulin response was lower, and no significant changes were noted for the p-IR, p-Akt, or active FoxO1 levels in the liver. In the QFM, the p-Akt level was increased in W-CR and Tg-AL rats with an insignificant elevation of p-IR levels. The phenotypic similarity of $\mathrm{W}-\mathrm{CR}$ and $\mathrm{Tg}-\mathrm{AL}$ rats suggest that $\mathrm{CR}$ minimizes activation of insulin signaling in response to energy intake mostly through the GH-IGF-1 axis.
\end{abstract}




\section{Introduction}

Calorie restriction (CR) and down-regulation of the growth hormone (GH)-insulin-like growth factor 1 (IGF-1) signaling pathway extend lifespan in various organisms (Longo and Fabrizio, 2002; Longo and Finch, 2003). We previously reported that transgenic (Tg) dwarf rats, in which the GH-IGF-1 axis was selectively suppressed by overexpression of an antisense GH transgene, showed a longer lifespan than wild-type (W) rats fed ad libitum (AL) (Shimokawa et al., 2003). Tg rats fed AL shared phenotypes with W rats subjected to $30 \% \mathrm{CR}$. The food intake and body weight in Tg-AL rats were similar to those in W-CR rats (Shimokawa et al., 2003). W-CR and Tg-AL rats also had normal or slightly improved glucose tolerance without a significant surge in the serum insulin concentration after glucose loading (Yamaza et al., 2004). Plasma adiponectin was increased in W-CR and Tg-AL rats, while plasma leptin was decreased (Yamaza et al., 2007). Elevation of adiponectin is involved in the sensitization of insulin action (Havel, 2004). Since CR is known to suppress the GH-IGF-1 axis (Breese et al., 1991; Dunn et al., 1997; Goya et al., 2002; Shimokawa et al., 2003), it may be hypothesized that CR modulates the insulin signaling stimulated by glucose via suppression of the GH-IGF-1 axis.

Binding of insulin to its receptor on the cell membrane leads to activation of the receptor tyrosine proteins that phosphorylate insulin receptor substrate (IRS) proteins (Rhodes and White, 2002). Tyrosine-phosphorylated IRS proteins then activate phosphatidylinositol 3-kinase (PI3K) and its downstream kinases, including Akt. In turn, Akt phosphorylates and inactivates FoxO1, a transcription factor that belongs to the mammalian orthologues of Daf16, a key transcription factor for extension of lifespan in Caenorhabditis (C) elegans under conditions of reduction-of-function mutation of Daf-2 or Age-1, i.e., the insulin-like signaling in C. elegans (Ogg et al., 1997; Pinkston et al., 2006). Thus, CR could partly exert its antiaging and life-prolonging effects through modulation of the insulin receptor (IR)-Akt-FoxO pathway. However, evidence for this is currently limited in mammals.

In the present study, to analyze CR-specific modulation of insulin signaling and 
evaluate the similarity between the effects of CR and suppression of the GH-IGF-1 axis on insulin signaling, we assessed glucose-stimulated insulin responses, phosphorylation (p) levels of IR and Akt, and active FoxO1 levels for DNA binding in the liver and skeletal muscle in $\mathrm{W}-\mathrm{CR}$ and Tg-AL rats. 


\section{Materials and Methods}

Animals and experimental protocol

The present study was conducted in accordance with the provisions of the Ethics Review Committee for Animal Experimentation at Nagasaki University. The Tg rat (Jcl: Wistar-TgN [ARGHGEN] 1Nts) colony has been maintained at the Biomedical Research Center at the Center for Frontier Life Sciences, Nagasaki University, since 1997, when pairs of Tg rats were kindly provided by the Nippon Institute for Biological Science (Oume City, Tokyo, Japan). The transgene consists of four copies of the thyroid hormone response element, the rat GH promoter and antisense cDNA sequences for rat GH (Matsumoto et al., 1993). Male rats heterozygous for the transgene (tg/-) were used, since these rats manifest similar phenotypes to W male Wistar (-/-) rats subjected to 30\% CR (Shimokawa et al., 2003). W rats were purchased from Japan Clea Inc. (Tokyo, Japan).

At 4 weeks of age, weanling male rats were transferred to a barrier facility (temperature, $22-25{ }^{\circ} \mathrm{C} ; 12-\mathrm{h}$ light/dark cycle), maintained separately under specific pathogen-free conditions and were fed AL with Charles River-LPF diet (Oriental Yeast Co. Ltd., Tsukuba, Japan). The composition of the food is as follows (per 100g); $18.2 \mathrm{~g}$ protein, $4.8 \mathrm{~g}$ fat, $6.6 \mathrm{~g}$ mineral mixture, $5.0 \mathrm{~g}$ fiber, $57.9 \mathrm{~g}$ nitrogen-free water-soluble substance, $7.5 \mathrm{~g}$ water. The caloric value of the food was $348 \mathrm{kcal} / 100 \mathrm{~g}$. At 6 weeks of age, 30\% CR was started by providing two lots of food every other day, with each food lot consisting of $70 \%$ of the mean daily food intake of $\mathrm{W}$ rats fed AL. The food lots for CR rats were adjusted depending on the amount of food consumed by W-AL rats every week until 12 weeks of age and every 2 weeks thereafter. Rats in each group were randomly assigned to a glucose or a saline injection group ( $n=5$ in $W$-AL and $W-C R$ and $n=4$ in Tg-AL). All rats were fasted overnight and sacrificed by decapitation at $15 \mathrm{~min}$ after intraperitoneal injection of $50 \%$ solution of glucose adjusted to 1.0 $\mathrm{g} / \mathrm{kg}$ body weight or vehicle (physiological saline); thus, approximately $1.08 \mathrm{ml}, 0.74 \mathrm{ml}$, and $0.67 \mathrm{ml}$ of glucose solution or saline was injected to $\mathrm{W}-\mathrm{AL}, \mathrm{W}-\mathrm{CR}$ and $\mathrm{Tg}$-AL respectively 
(refer to Table 1 for body weights). After decapitation, trunk blood was collected, and serum and plasma samples were prepared and stored at $-30{ }^{\circ} \mathrm{C}$ until assayed for insulin and adiponectin. The liver and quadriceps femoris muscle (QFM) tissues were immediately collected, diced, quickly frozen in liquid nitrogen and stored at $-80{ }^{\circ} \mathrm{C}$ until assays for the levels of p-IR, p-Akt and foxO1 DNA-binding activity.

\section{Measurements of serum insulin, glucose, and plasma adiponectin}

Serum insulin concentrations were measured using enzyme-linked immunosorbent assay (ELISA) kits specific for rat insulin (Amersham Laboratories Inc., Webster, TX). The plasma concentrations of adiponectin was also measured using ELISA kits specific for rat and mouse adiponectin (Otsuka Pharmaceutical Co. Ltd., Tokyo, Japan). Serum glucose concentrations were measured using kits based on the glucose oxidase method (Wako Pure Chemical Industries Ltd., Osaka, Japan).

\section{ELISA for $p$-IR and $p$-Akt}

For measurements of $\mathrm{p}$-IR and $\mathrm{p}$-Akt, total protein was extracted from the liver and QFM using lysis buffer (50 mM Tris- $\mathrm{HCl}$ pH 7.4, $150 \mathrm{mM} \mathrm{NaCl}, 1 \%$ Nonidet P-40 (NP-40), 1\% Triton X-100, $1 \mathrm{mM}$ ethylenediaminetetraacetic acid (EDTA), $50 \mathrm{mM} \mathrm{NaF}, 1 \mathrm{mM}$ sodium orthovanadate, $1 \mathrm{mM}$ phenylmethylsulfonyl fluoride (PMSF), $5 \mathrm{~g} / \mathrm{ml}$ aprotinin). The protein levels of p-IR and p-Akt were determined using an Insulin Receptor [pYpY1162/1163] ELISA kit and Akt [pS473] ELISA kit (both from BioSource International, Camarillo, CA), respectively. All samples were tested in duplicate. The optical density (OD) of each sample was read at 450 nm using a Labsystems Multiskan (Dainihonseiyaku, Tokyo, Japan).

In preliminarily experiments, we also performed western blot analyses of IR and Akt proteins in liver and QFM tissues of W-AL and W-CR rats. There were no significant differences in levels of IR or Akt between the rat groups (Supplemental figure 1 and 2). p-IR 
and p-Akt levels were also analyzed by western blots. The results showed trends similar to those obtained by ELISA (Supplemental figure 1 and 2).

Preparation of nuclear extracts from liver and FoxO1 DNA-binding assay

To measure the FoxO1 DNA-binding activity, a modified fractionation protocol was used as previously described (Corsini et al., 1997). Briefly, nuclear extracts were extracted from minced liver (200 mg) and homogenized for $30 \mathrm{~s}$ in $1.2 \mathrm{ml}$ of a hypotonic lysis buffer (buffer A: 10 mM HEPES pH 7.8, 10 mM KCl, 2 mM MgCl2, 1 mM DTT, 0.1 mM EDTA, 0.1 mM PMSF, 5 $\mu \mathrm{g} / \mathrm{ml}$ aprotinin, $2 \mu \mathrm{g} / \mathrm{ml}$ leupeptin, $1 \mu \mathrm{g} / \mathrm{ml}$ pepstatin, $1 \mathrm{mM}$ sodium orthovanadate, $20 \mathrm{mM}$ $\mathrm{NaF}$ ) using a tissue homogenizer. After incubating the resulting homogenates on ice for $20 \mathrm{~min}$, $150 \mu \mathrm{l}$ of a $10 \% \mathrm{NP}-40$ solution was added and mixed for $15 \mathrm{~s}$, before the mixture was centrifuged at 13,000 $\mathrm{g}$ for $2 \mathrm{~min}$. The pelleted nuclei were washed twice with $200 \mu \mathrm{l}$ of buffer A plus $25 \mu \mathrm{l}$ of $10 \% \mathrm{NP}-40$, centrifuged, suspended in $100 \mu \mathrm{l}$ of buffer B (50 mM HEPES pH 7.8,

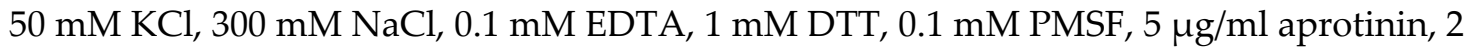
$\mu \mathrm{g} / \mathrm{ml}$ leupeptin, $1 \mu \mathrm{g} / \mathrm{ml}$ pepstatin, $1 \mathrm{mM}$ sodium orthovanadate, $20 \mathrm{mM} \mathrm{NaF}, 10 \%$ (vol/vol) glycerol), mixed for $30 \mathrm{~min}$ and centrifuged at 13,000 $\mathrm{g}$ for $10 \mathrm{~min}$. After harvesting the supernatant containing nuclear proteins, the protein concentration was determined and the supernatant was stored at $-80^{\circ} \mathrm{C}$ until use in transcription factor assays. The FoxO1 DNA-binding activities were determined using TransAMTM FKHR (FOXO1) Transcription Factor Assay Kits from Active Motif (Carlsbad, CA). All samples were tested in duplicate. The ODs of the samples at $450 \mathrm{~nm}$ were measured using the above-mentioned Labsystems Multiskan. The whole QFM lysate was used for this assay because the FoxO1 DNA-binding activity was too low to be detected in the nuclear fraction.

\section{Statistical analysis}

Data are expressed as means \pm SD and were analyzed by one-factor (1-f) ANOVA 
followed by Fisher's protected least significance difference (PLSD) test using StatView (SAS Institute Inc., Cary, NC). Serum insulin and glucose data were analyzed after logarithmic transformation to stabilize variations in the data. Values of $p<0.05$ were considered significant. Values of $p<0.1000$ are also inserted in the text to indicate possible differences. 


\section{Results}

General data

The average body weights were $32 \%$ and $35 \%$ lower in W-CR and Tg-AL rats than $\mathrm{W}$-AL rats (both: $\mathrm{p}<0.0001$; Table 1 ). The body weight in $\mathrm{W}-\mathrm{CR}$ rats was slightly greater than that in Tg-AL rats $(\mathrm{p}=0.0009)$.

The peri-renal fat pad weight, which was normalized by body weight, was $36 \%$ less in $\mathrm{W}-\mathrm{CR}(\mathrm{p}<0.0001)$ and $29 \%$ less in Tg-AL rats $(\mathrm{p}<0.0001)$ than $\mathrm{W}-\mathrm{AL}$ rats. There was no difference between $\mathrm{W}-\mathrm{CR}$ and Tg-AL rats.

Blood glucose concentrations were significantly greater in the glucose-injected groups than in saline-groups in all three groups of rat ( $\mathrm{p}<0.0001$ in $\mathrm{W}-\mathrm{AL}, \mathrm{W}-\mathrm{CR}$, and Tg-AL rats). Although the glucose levels in the saline-injected rats did not differ between the three groups of rats, the blood glucose levels after glucose injection were 15\% lower in $\mathrm{W}-\mathrm{CR}(\mathrm{p}=0.0302)$ and $20 \%$ in Tg-AL rats $(p=0.0055)$ than in $\mathrm{W}-\mathrm{AL}$ rats.

The serum insulin level in the saline-injected Tg-AL rats was lower than that in W-AL rats $(p=0.0420)$. There was no statistical difference in the insulin level between $W-C R$ and W-AL saline-injected groups. The serum insulin levels were greater in the glucose-injected groups compared with the saline-injected groups in all three rat groups $(\mathrm{p}=0.0013$ in $\mathrm{W}-\mathrm{AL}, \mathrm{p}$ $=0.0096$ in $\mathrm{W}-\mathrm{CR}$, and $\mathrm{p}=0.0127$ in Tg-AL rats). The insulin levels in the glucose-injected groups were significantly lower in $\mathrm{W}-\mathrm{CR}$ rats $(\mathrm{p}=0.0477)$ and Tg-AL $(\mathrm{p}=0.0109)$ rats compared with $\mathrm{W}-\mathrm{AL}$ rats. There was no difference between $\mathrm{W}-\mathrm{CR}$ and Tg-AL rats.

The plasma adiponectin concentrations did not differ statistically between the saline-injected and the glucose-injected groups in the three rat groups. The concentrations were greater in $\mathrm{W}-\mathrm{CR}(\mathrm{p}=0.0003$ in the saline-injected group and $\mathrm{p}=0.0057$ in the glucose-injected group) and Tg-AL ( $\mathrm{p}=0.0008$ in the saline-injected group, but not significant in the glucose-injected group) rats than in W-AL rats. 
Levels of $p-I R$

In the liver (Fig. 1A), the p-IR levels in the saline-injected group did not differ between the three rat groups. The p-IR level was significantly greater in the glucose-injected group than in the saline-group in $\mathrm{W}-\mathrm{AL}$ rats $(\mathrm{p}=0.0057)$. In $\mathrm{W}-\mathrm{CR}$ and Tg-AL rats, the $\mathrm{p}-\mathrm{IR}$ levels in the glucose-injected groups did not differ from those in the saline-injected groups. Furthermore, the p-IR levels in the glucose-injected groups were lower in $\mathrm{W}-\mathrm{CR}$ and Tg-AL rats compared with $\mathrm{W}-\mathrm{AL}$ rats $(\mathrm{p}=0.0024$ in $\mathrm{W}-\mathrm{CR}$ and $\mathrm{p}=0.0426$ in Tg-AL).

In the QFM (Fig. 1B), the p-IR levels in the saline-injected groups did not differ between the three rat groups. The p-IR level was significantly greater in the glucose-injected group than the saline-injected group in $\mathrm{W}-\mathrm{AL}$ rats $(\mathrm{p}=0.0022)$. In $\mathrm{W}-\mathrm{CR}$ and Tg-AL rats, the p-IR levels did not differ between the glucose-injected and saline-injected groups. Furthermore, in the glucose-injected groups, the p-IR level was greater in W-AL rats compared with the $\mathrm{W}-\mathrm{CR}$ and Tg-AL rats $(\mathrm{p}=0.0149$ and $\mathrm{p}=0.0003$ respectively).

Levels of $p$-Akt

In the liver (Fig. 2A), the p-Akt levels in the saline-injected groups did not differ between the three rat groups. The p-Akt level in the glucose-injected group was greater than the saline-injected group in W-AL rats $(\mathrm{p}=0.0005)$; in Tg-AL rats, the level was marginally higher $(\mathrm{p}=0.0632)$ in the glucose-injected group compared with the saline-injected group. There was no difference between the glucose- and saline-injected groups in W-CR rats. The p-Akt level in the glucose-injected groups was significantly greater in W-AL rats than in Tg-AL rats $(p=0.0272)$, but only marginally greater than in $\mathrm{W}-\mathrm{CR}$ rats $(\mathrm{p}=0.0612)$.

In the QFM (Fig. 2B), the p-Akt levels in the saline-injected groups did not differ between the three rat groups. The p-Akt levels in the glucose-injected groups were significantly greater than in the saline-injected groups in all three rat groups $(p=0.0001$ in $\mathrm{W}-\mathrm{AL}, \mathrm{p}=0.0004$ in $\mathrm{W}-\mathrm{CR}$, and $\mathrm{p}=0.0449$ in Tg-AL). The $\mathrm{p}-\mathrm{Akt}$ levels did not differ between 
the three glucose-injected rat groups.

Active FoxO1 levels for DNA binding

In the liver (Fig 3A), the active FoxO1 levels in the saline-injected groups did not differ between the three groups. In W-AL rats, the level in the glucose-injected group was lower than in the saline-injected group $(\mathrm{p}=0.0043)$. In $\mathrm{W}-\mathrm{CR}$ and $\mathrm{Tg}-\mathrm{AL}$ rats, the FoxO1 levels did not differ significantly between the glucose-injected and saline-injected groups. The FoxO1 levels did not differ significantly between the three glucose-injected rat groups.

In the QFM (Fig. 3B), the active FoxO1 levels in the saline-injected groups did not differ significantly between the three rat groups, although there seemed to be a small difference between $\mathrm{W}-\mathrm{AL}$ and $\mathrm{Tg}-\mathrm{AL}$ rats $(\mathrm{p}=0.0642)$. There was no significant difference in the FoxO1 level between the glucose-injected and saline-injected groups in each rat group, although there was a marginal difference in $\mathrm{W}-\mathrm{CR}$ rats $(\mathrm{p}=0.0682)$. The active FoxO1 level in the glucose-injected group was marginally lower in $\mathrm{W}-\mathrm{CR}$ rats than in $\mathrm{W}-\mathrm{AL}$ rats $(\mathrm{p}=0.0818)$.

\section{Discussion}

In the present study, we confirmed the presence of a glucose-stimulated elevation in serum insulin levels and subsequent activation (phosphorylation) of IR and Akt in both the liver and QFM in control W-AL rats. The level of active FoxO1, which is phosphorylated and

inactivated by Akt (Rena et al., 1999; Biggs et al., 1999), was also decreased in the liver, but not significantly in the QFM. The present study also showed that CR minimized the magnitude of the elevation of serum insulin levels and activation of IR-Akt signaling in response to elevated glucose levels, thereby also reducing the inactivation of FoxO1, at least in the liver.

GH-suppressed Tg rats exhibited responses broadly similar to those in W-CR rats with respect to insulin signaling. The plasma IGF-1 concentration, an index of suppression of the GH axis, was $23 \%$ and $40 \%$ lower in $\mathrm{W}-\mathrm{CR}$ and Tg-AL rats, respectively, compared with $\mathrm{W}$-AL rats at 6 
months of age (Shimokawa et al., 2003). The phenotypic similarity supports the hypothesis that CR primarily reduces the activation of insulin signaling for glucose metabolism through reduction of GH and/or subsequent IGF-1 signaling.

In W-CR and Tg-AL rats, the blood glucose level after glucose injection was slightly lower than in $\mathrm{W}$-AL rats, as was the subsequent serum insulin response. In our previous study using the same experimental setting, we demonstrated that blood glucose levels significantly increased $15 \mathrm{~min}$ after glucose injection, but returned to an almost basal level more quickly in CR rats (Yamaza et al., 2004). Another study (Wetter et al., 1999) has also demonstrated that glucose injected intravenously was slightly but more quickly cleared from the circulation with lower levels of insulin in CR rats, while glucose uptake by some tissues was increased. Thus, the lower glucose and insulin levels after a glucose load in CR rats could be a result of the promotion of glucose uptake in tissues by CR with lower serum insulin levels.

A reduced serum concentration of insulin has been correlated with sensitization to insulin signaling (Masoro 2005) implying that the p-IR and Akt levels are elevated similarly or to a greater extent in $\mathrm{CR}$ rodent tissues with a lower serum insulin response to glucose. However, a reduced activation of insulin signaling in response to energy intake may favor longevity in animals. This trait leads to the evasion of inactivation of FoxO transcription factors, which are mammalian orthologues of Daf 16 (Ogg et al., 1997) that is required for lifespan extension in the presence of reduction-of-function mutations in insulin-like signaling in C. elegans (Kenyon et al., 1993; Ogg et al., 1997; Pinkston et al., 2006). The present results in the liver support this hypothesis.

Post-translational modifications of FoxO1 protein by phosphorylation and acetylation acutely reduces the activity of FoxO1 (Matsuzaki et al., 2005) as was the case in the W-AL rats. However, one can also expect that chronic CR elevates the steady state FoxO1 levels. In the liver of $\mathrm{CR}$ and GHR-KO mice, FoxO1 mRNA levels are reported to increase, but the protein level in whole lysates of the tissue does not (Al-Regaiey et al., 2005). The present data also indicated that CR or suppression of the GH-IGF-1 axis did not directly affect the active FoxO1 levels in the liver under unstimulated conditions. Thus, it can be concluded that long-term CR 
or GH suppression affects hepatic FoxO1 activity through the effect on insulin signaling, but does not directly alter the steady state protein abundance.

A recent study has shown that fasting-activated FoxO1 promotes fatty acid influx in muscle cells and fatty acid oxidation, and suppresses glucose oxidation (Bastie et al., 2005). These findings are also characteristic of the metabolic adaptation of chronic CR. However, FoxO1 protein levels are reported to decrease in the skeletal muscle of CR mice and GHR-KO mice at baseline (Al-Regaiey et al., 2007). In the present study, the active FoxO1 level was also not increased in W-CR rats; on the contrary, the level seemed to be lower in the glucose-injected group of W-CR rats and the saline-injected Tg-AL rats group compared with the respective W-AL groups. In the present study, the level of active FoxO1 in the QFM was measured in whole cell lysates, as was the case in the other study (Al-Regaiey, et al., 2007), because the protein levels in the nuclear fractions were too low for measurement, and thus the assay might not be so sensitive. In this respect, the present data for FoxO1 in the QFM are limited. However, FoxO1 is reported to suppress the differentiation of muscle cells and to inhibit increases in skeletal muscle mass in response to growth factor stimuli (Kamei et al., 2004). Lean body mass, normalized for body weight, is not decreased in CR rodents with advancing age (McCarter et al., 1992; Barzilai et al., 1998). Therefore, it is unlikely that FoxO1 activity is constitutively upregulated in the CR rat muscle.

The present study could not detect a significant reduction of FoxO1 levels after the glucose load in any group of rats, although the p-Akt levels were equally elevated in all three groups. One possibility is that Akt is not a major regulator of FoxO1 activity in the muscle. A potential role for FoxO1 in the metabolic adaptation and maintenance of muscle mass under CR conditions should be investigated.

Normal or facilitated glucose uptake into tissues with lower serum insulin is characteristic of the effects of CR (Masoro et al., 1992; Wetter et al., 1999). Previous reports have emphasized the sensitization of insulin signaling in skeletal muscle tissues in CR animals and long-lived dwarf mice, using in vivo and in vitro experiments in which relatively high doses of insulin are administered (Gazdag et al., 1999; McCurdy et al., 2003; McCurdy et al., 
2005). In the present study, the p-Akt level was significantly elevated with a modest increase in serum insulin and an insignificant increase in p-IR in the QFM of W-CR and Tg-AL rats. The activated state of Akt in the QFM was different from that in the liver. These results indicate sensitization of insulin action in the skeletal muscle by CR and GH suppression. Indeed, our previous study demonstrated an increase in whole body insulin sensitivity in W-CR and Tg-AL rats using insulin tolerance tests (Yamaza $\mathrm{H}$ et al., 2004). Because skeletal muscle is a major insulin-dependent organ, the enhanced whole body insulin sensitivity in CR and Tg rats could be mostly due to the increased insulin sensitivity in skeletal muscles by $\mathrm{CR}$ or GH suppression.

Although the blood lipid levels, particularly free fatty acids (FFA), are known to affect insulin sensitivity, there was no significant difference in blood FFA between the three rat groups (Supplemental table 1). In contrast, recent studies have indicated a role for adiponectin in glucose uptake by muscles in an insulin-independent manner as well as an insulin-dependent mechanism (Habel PJ. 2004). The present study demonstrated that the plasma adiponectin concentrations were increased in both W-CR and in Tg-AL rats, although they did not respond to glucose injection. Adiponectin is reported to promote glucose uptake in skeletal muscle through activation of AMPK (Habel PJ. 2004). There is, however, no evidence indicating that AMPK and/or downstream molecules directly phosphorylate Akt. Thus, a potential alternative pathway that bypasses the IR but activates Akt in CR rat skeletal muscles remains to be elucidated.

Our previous studies as well as the present study demonstrated that Tg-AL rats had phenotypes similar to W-CR rats with respect to body weight, food intake, fat content, glucose tolerance, insulin sensitivity, and adiopokines such as adiponectin and leptin (Yamaza et al., 2004; Yamaza et al., 2007). A preliminary experiment also indicated stress resistance, one of the traits of CR animals, in Tg-AL rats (Shimokawa 2006). Because CR suppresses the GH-IGF-1 axis, data from Tg-AL rats support the importance of the GH-IGF-1 axis for the effect of CR. However, it should be noted that GH-IGF-1 signaling is merely one of the signaling pathways that mediates the effects of CR. CR suppresses the gonadal, thyroid, and GH-IGF-1 axes, but 
activates the adrenal glucocorticoid system (Nelson 1994). Gerontologists have understood that these neuroendocrine alterations could be responses of organisms to maximize survival during periods of food shortage (Masoro, et al. 1996). Recent studies have shown that modulation of some neuroendocrine signaling pathways or systems without caloric restriction could also, to some extent, retard aging or extend the lifespan of animals, if experimentally modulated as with CR. For example, chemical ablation of the thyroidal axis extended lifespan in rats (Ooka et al., 1986). In contrast, CR also leads to life-prolonging effects in Ames dwarf mice deficient of pituitary GH, prolactin, and thyroid-stimulating hormone (Bartke, et al. 2001), suggesting the presence of CR-specific mechanisms unrelated with these pituitary hormones.

In conclusion, the present study has demonstrated that $\mathrm{CR}$ and moderate suppression of GH minimize the activation of insulin signaling in response to glucose loading to a similar extent, suggesting the importance of the GH-IGF-1 axis in the effects of CR. The effects of CR on insulin signaling could be in line with the longevity-assuring mechanism in C. elegans that involves Daf-16.

\section{Acknowledgements}

We are grateful to Yutaka Araki and the staff in the Laboratory Animal Center at Nagasaki University School of Medicine for their excellent technical support. This work was supported by Grants-in-Aid for Science Research from the Japan Society for the Promotion of Science (no. 15390128 and 16790226). 


\section{References}

Ader M., Pacini G., Yang Y.J., Bergman R.N., 1985. Importance of glucose per se to intravenous glucose tolerance. Diabetes 34, 1092-1103.

Al-Regaiey K.A., Masternak M.M., Bonkowski M.S., Panici J.A., Kopchick J.J., Bartke, A., 2007. Effects of caloric restriction and growth hormone resistance on insulin-related intermediates in the skeletal muscle. J. Gerontol. A Biol. Sci. Med. Sci. 62, 18-26.

Al-Regaiey K.A., Masternak M.M., Bonkowski M.S., Sun L., Bartke A., 2005. Long-lived growth hormone receptor knockout mice: interaction of reduced IGF/insulin signaling and caloric restriction. Endocrinology 146, 851-860.

Bartke A., Wright C., Mattison J.A., Ingram D.K., Miller R.A., Roth G.S., 2001. Extending the lifespan of long-lived mice. Nature $414,412$.

Barzilai N., Banerjee S., Hawkins M., Chen W., Rossetti L., 1998. Caloric restriction reverses hepatic insulin resistance in aging rats by decreasing visceral fat. J. Clin. Invest. 101, 1353-1361.

Bastie C.C., Nahle Z., McLoughlin T., Esser K., Zhang W., Unterman T., Abumrad N.A., 2005. FoxO1 stimulates fatty acid uptake and oxidation in muscle cells through CD36-dependent and -independent mechanisms. J. Biol. Chem. 280, 14222-14229.

Biggs W.H., Meisenhelder J., Hunter T., Cavenee W.K., Arden K.C., 1999. Protein kinase B/Akt-mediated phosphorylation promotes nuclear exclusion of the winged helix transcription factor FKHR1. Proc. Natl. Acad. Sci. USA 96, 7421-7426.

Breese C.R., Ingram R.L., Sonntag W.E., 1991. Influence of age and long-term dietary restriction 
on plasma insulin-like growth factor-1 (IGF-1), IGF-1 gene expression, and IGF-1 binding proteins. J. Gerontol. 46, B180-B187.

Brunet A., Bonni A., Zigmond M.J., Lin M.Z., Juo P., Hu L.S., Anderson M.J., Arden K.C., Blenis J., Greenberg M.E., 1999. Akt promotes cell survival by phosphorylating and inhibiting a Forkhead transcription factor. Cell 96, 857-868.

Corsini E., Terzoli A., Bruccoleri A., Marinovich M., Galli C.L., 1997. Induction of tumor necrosis factor-alpha in vivo by a skin irritant, tributyltin, through activation of transcription factors: its pharmacological modulation by anti-inflammatory drugs. J. Invest. Dermatol. 108, 892-896.

Cushman S.W., Wardzala L.J., 1980. Potential mechanism of insulin action on glucose transport in the isolated rat adipose cell. J. Biol. Chem. 255, 4758-4762.

Dunn S.E., Kari F.W., French J., Leininger J.R., Travlos G., Wilson R., Barrett J.G., 1997. Dietary restriction reduces insulin-like growth factor I levels, which modulates apoptosis, cell proliferation, and tumor progression in p53-deficient mice. Cancer Res. 57, 4667-4672.

Gazdag A.C., Dumke C.L., Kahn C.R., Cartee G.D., 1999. Calorie restriction increases insulin-stimulated glucose transport in skeletal muscle from IRS-1 knockout mice. Diabetes 48, 1930-1936.

Goya L., Garcia-Segura L.M., Ramos S., Pascual-Leone A.M., Argente J., Martin M.A., Chowen J.A., 2002. Interaction between malnutrition and ovarian hormones on the systemic IGF-I axis. Eur. J. Endocrinol. 147, 417-424.

Hanson R.W., Reshef L., 1997. Regulation of phosphoenolpyruvate carboxykinase (GTP) gene 
expression. Annu. Rev. Biochem. 66, 581-611.

Havel P.J., 2004. Update on adipocyte hormones: regulation of energy balance and carbohydrate/lipid metabolism. Diabetes 53, S143-S151.

Kamei Y., Miura S., Suzuki M., Kai Y., Mizukami J., Taniguchi T., Mochida K., Hata T., Matsuda J., Aburatani H., Nishino I., Ezaki O., 2004. Skeletal muscle FOXO1 (FKHR) transgenic mice have less skeletal muscle mass, down-regulated type I (slow twitch/red muscle) fiber genes, and impaired glycemic control. J. Biol. Chem. 279, 41114-41123.

Kenyon C., Chang J., Gensch E., Rudner A., Tabtlang R., 1993. A C. elegans mutant that lives twice as long as wild type. Nature 366, 461-464.

Kops G.J., de Ruiter N.D., De Vries-Smits A.M., Powell D.R., Bos J.L., Burgering B.M., 1999. Direct control of the Forkhead transcription factor AFX by protein kinase B. Nature 398, 630-634.

Lang C.H., 1992. Rates and tissue sites of noninsulin- and insulin-mediated glucose uptake in diabetic rats. Proc. Soc. Exp. Biol. Med. 199, 81-87.

Longo V.D., Fabrizio P., 2002. Regulation of longevity and stress resistance: a molecular strategy conserved from yeast to humans? Cell Mol. Life Sci. 59, 903-908.

Longo V.D., Finch C.E., 2003. Evolutionary medicine: from dwarf model systems to healthy centenarians? Science 299, 1342-1346.

Masoro E.J., McCarter R.J., Kats M.S., McMahan C.A., 1992. Dietary restriction alters characteristics of glucose fuel use. J. Gerontol. 47, B202-B208. 
Masoro E.J., Austad S.N., 1996. The evolution of the antiaging action of dietary restriction: a hypothesis. J Gerontol A Biol Sci Med Sci. 51, B387-391.

Masoro E.J., 2005. Overview of caloric restriction and ageing. Mech. Ageing Develop. 126, 913-922.

Masternak M.M., Al-Regaiey K.A., Bonkowski M.S., Panici J.A., Bartke A., 2005. Effect of every other day feeding diet on gene expression in normal and in long-lived Ames dwarf mice. Exp. Gerontol. 40, 491-497.

Matsumoto K., Kakidani H., Takahashi A., Nakagata N., Anzai M., Matsuzaki Y., Takahashi Y., Miyata K., Utsumi K., Iritani A., 1993. Growth retardation in rats whose growth hormone gene expression was suppressed by antisense RNA transgene. Mol. Reprod. Dev. 36, 53-58.

Matsuzaki H., Daitoku H., Hatta M., Aoyama H., Yoshimochi K., Fukamizu A., 2005.

Acetylation of Foxo1 alters its DNA-binding ability and sensitivity to phosphorylation. Proc. Natl. Acad. Sci. USA 102, 11278-11283.

McCarter R.J., Palmer J., 1992. Energy metabolism and aging: a lifelong study of Fischer 344 rats. Am. J. Physiol. 263, E448-E452.

McCurdy C.E., Davidson R.T., Cartee G.D., 2003. Brief calorie restriction increases Akt2 phosphorylation in insulin-stimulated rat skeletal muscle. Am. J. Physiol. Endocrinol. Metab. 285, E693-E700.

McCurdy C.E., Cartee G.D., 2005. Akt2 is essential for the full effect of calorie restriction on insulin-stimulated glucose uptake in skeletal muscle. Diabetes 54, 1349-1356. 
Nelson J.F., 1994. Neuroendocrine involvement in the retardation of aging by dietary restriction: A hypothesis. Yu, B.P. (ed), Modulation of aging processes by dietary restriction. CRC Press, Inc. pp. 37-55.

Ogg S., Paradis S., Gottlieb S., Patterson G.I., Lee L., Tissenbaum H.A., Ruvkun G., 1997. The Fork head transcription factor DAF-16 transduces insulin-like metabolic and longevity signals in C. elegans. Nature 389, 994-999.

Paik J.H., Kollipara R., Chu G., Ji H., Xiao Y., Ding Z., Miao, L., Tothova Z., Horner J.W., Carrasco D.R., Jiang S., Gilliland D.G., Chin L., Wong W.H., Castrillon D.H., DePinho R.A., 2007. FoxOs are lineage-restricted redundant tumor suppressors and regulate endothelial cell homeostasis. Cell 128, 309-323.

Park S., Komatsu T., Hayashi H., Yamaza H., Chiba T., Higami Y., Kuramoto K., Shimokawa I., 2006. Calorie restriction initiated at middle age improved glucose tolerance without affecting age-related impairments of insulin signaling in rat skeletal muscle. Exp. Gerontol. 41, 837-745.

Pinkston J.M., Garigan D., Hansen M., Kenyon C., 2006. Mutations that increase the life span of C. elegans inhibit tumor growth. Science 313, 971-975.

Puigserver P., Rhee J., Donovan J., Walkey C.J., Yoon J.C., Oriente F., Kitamura Y., Altomonte J., Dong H., Accili D., Spiegelman B.M., 2003. Insulin-regulated hepatic gluconeogenesis through FOXO1-PGC-1fi interaction. Nature 423, 550-555.

Rena G., Guo S., Cichy S.C., Unterman T.G., Cohen P., 1999. Phosphorylation of the transcription factor forkhead family member FKHR by protein kinase B. J. Biol. Chem. 274, 17179-17183. 
Rhodes C.J., White M.F., 2002. Molecular insights into insulin action and secretion. Eur. J. Clin. Invest. 32, 3-13.

Shimokawa I., Higami Y., Tsuchiya T., Otani H., Komatsu T., Chiba T., Yamaza H., 2003. Lifespan extension by reduction of the growth hormone-insulin-like growth factor- 1 axis: relation to caloric restriction. FASEB J. 17, 1108-1109.

Shimokawa I., 2006. A transgenic mini rat strain as a tool for studying aging and calorie restriction. Conn, P.M. (ed), Elsevier Academic Press pp. 367-378.

Suzuki K., Kono T., 1980. Evidence that insulin causes translocation of glucose transport activity to the plasma membrane from an intracellular storage site. Proc. Natl. Acad. Sci. USA $77,2542-2545$.

Takaishi H., Konishi H., Matsuzaki H., Ono Y., Shirai Y., Saito N., Kitamura T., Ogawa W., Kasuga M., Kikkawa U., Nishizuka Y., 1999. Regulation of nuclear translocation of Forkhead transcription factor AFX by protein kinase B. Proc. Natl. Acad. Sci. USA 96, 11836-11841.

Tothova Z., Kollipara R., Huntly B.J., Lee B.H., Castrillon D.H., Cullen D.E., McDowell E.P., Lazo-Kallanian S., Williams I.R., Sears C., Armstrong S.A., Passegue E., DePinho R.A., Gilliland D.G., 2007. FoxOs are critical mediators of hematopoietic stem cell resistance to physiologic oxidative stress. Cell 128, 325-339.

Yamaza H., Komatsu T., Chiba T., Toyama H., To K., Higami Y., Shimokawa I., 2004. A transgenic dwarf rat model as a tool for the study of calorie restriction and aging. Exp. Gerontol. 39, 269-272. 
Yamaza H., Komatsu T., To K., Toyama H., Chiba T., Higami Y., Shimokawa I., 2007.

Involvement of insulin-like growth factor-1 in the effect of caloric restriction: regulation of plasma adiponectin and leptin. J. Gerontol. A Biol. Sci. Med. Sci. 62, 27-33.

Wan R., Camandola S., Mattson M.P., 2003. Intermittent fasting and dietary supplementation with 2-deoxy-D-glucose improve functional and metabolic cardiovascular risk factors in rats. FASEB J. 17, 1133-1134.

Wetter T.J., Gazdag A.C., Dean D.J., Cartee G.D., 1999. Effect of calorie restriction on in vivo glucose metabolism by individual tissues in rats. Am. J. Physiol. Soc. 276, E728-E738. 


\section{Figure legends}

Fig. 1. Levels of phosphorylated insulin receptor ( $p$-IR) detected by ELISA using whole extracts of livers (A) and quadriceps femoris muscles (QFM) (B) from wild-type ad libitum-fed rats (W-AL), 30\% calorie-restricted rats (W-CR) and transgenic rats fed ad libitum (Tg-AL). Each bar and line represent the mean $+\mathrm{SD}(\mathrm{n}=5$ for $\mathrm{W}-\mathrm{AL}$ and $\mathrm{W}-\mathrm{CR} ; \mathrm{n}=4$ for Tg-AL). Shared letters represent statistical differences at $\mathrm{p}<0.05$, determined by one-factor ANVOA with post hoc tests.

Fig. 2. Levels of phosphorylated Akt (Ser473) (p-Akt) detected by ELISA using whole extracts of livers (A) and quadriceps femoris muscles (QFM) (B) from wild-type ad libitum-fed rats (W-AL), 30\% calorie-restricted rats (W-CR) and transgenic rats fed ad libitum (Tg-AL). Each bar and line represent the mean $+\mathrm{SD}(\mathrm{n}=5$ for $\mathrm{W}-\mathrm{AL}$ and $\mathrm{W}-\mathrm{CR} ; \mathrm{n}=4$ for Tg-AL). Shared letters represent statistical differences at $\mathrm{p}<0.05$, determined by one-factor ANVOA with post hoc tests.

Fig. 3. FoxO1 DNA-binding activities in nuclear fractions of livers (A) and whole extracts of quadriceps femoris muscles (QFM) (B) from wild-type ad libitum-fed rats (W-AL), 30\% calorie-restricted rats (W-CR) and transgenic rats fed ad libitum (Tg-AL). Each bar and line represent the mean $+\mathrm{SD}(\mathrm{n}=5$ for $\mathrm{W}-\mathrm{AL}$ and $\mathrm{W}-\mathrm{CR} ; \mathrm{n}=4$ for Tg-AL). Shared letters represent statistical difference at $\mathrm{p}<0.05$, determined by one-factor ANVOA with post hoc tests. 


\section{Table 1}

Table 1. Body and fat pad weights and blood glucose, insulin, and adiponectin concentrations

\begin{tabular}{|c|c|c|c|c|c|c|}
\hline & \multicolumn{2}{|c|}{ W-AL } & \multicolumn{2}{|c|}{$\mathrm{W}-\mathrm{CR}$} & \multicolumn{2}{|c|}{$\mathrm{Tg}-\mathrm{AL}$} \\
\hline & Saline & Glucose & Saline & Glucose & Saline & Glucose \\
\hline Body weight (g) & \multicolumn{2}{|c|}{$544.4 \pm 11.8^{a}$} & \multicolumn{2}{|c|}{$372.4 \pm 26.1^{a}$} & \multicolumn{2}{|c|}{$335.6 \pm 23.5^{a}$} \\
\hline $\begin{array}{l}\text { Peri-renal fat ( } \mathrm{g} / 100 \\
\text { g body weight) }\end{array}$ & \multicolumn{2}{|c|}{$3.12 \pm 0.39 \mathrm{a} / \mathrm{b}$} & \multicolumn{2}{|c|}{$2.01 \pm 0.35 \mathrm{a}$} & \multicolumn{2}{|c|}{$2.22 \pm 0.33 b$} \\
\hline Glucose (mg/dl) & $110.5 \pm 11.7^{\mathrm{a}}$ & $322.3 \pm 20.9 \mathrm{a} / \mathrm{d}$ & $103.7 \pm 3.9^{b}$ & $272.6 \pm 32.4^{\mathrm{b} / \mathrm{d}}$ & $121.0 \pm 9.8^{c}$ & $257.9 \pm 58.2^{\mathrm{c} / \mathrm{d}}$ \\
\hline Insulin (ng/ml) & $80.7 \pm 35.0$ a/e & $1214.1 \pm 1764.7^{\mathrm{a}}$ & $37.9 \pm 13.0^{\mathrm{b}}$ & $299.6 \pm 377.6^{\mathrm{b} / \mathrm{d}}$ & $20.8 \pm 10.1^{c / e}$ & $301.0 \pm 457.3^{\mathrm{c} / \mathrm{d}}$ \\
\hline $\begin{array}{l}\text { Adiponectin } \\
(\mu \mathrm{g} / \mathrm{ml})\end{array}$ & $3.28 \pm 0.38 \mathrm{a} / \mathrm{b}$ & $3.77 \pm 0.77 \mathrm{c}$ & $4.81 \pm 0.65^{a}$ & $4.99 \pm 0.62^{c}$ & $4.92 \pm 0.92^{b}$ & $4.46 \pm 0.09$ \\
\hline
\end{tabular}

Notes: Data represent the mean $\pm \mathrm{SD}(\mathrm{n}=10$ for the body weight in $\mathrm{W}$-AL and $\mathrm{W}-\mathrm{CR} ; \mathrm{n}=8$ in Tg-AL. $\mathrm{n}=5$ for each treatment in $\mathrm{W}$-AL and $\mathrm{W}-\mathrm{CR}$ groups; $\mathrm{n}=4$ for each treatment in Tg-AL group). Shared letters indicate statistical difference, $\mathrm{p}<0.05$. Peri-renal fat pad weights were normalized by body weights. Data of glucose and insulin were statistically analyzed after log-transformation. W-AL, wild-type ad libitum-fed rats; W-CR, 30\% calorie-restricted rats; Tg-AL, transgenic rats fed ad libitum. 
Fig 1A

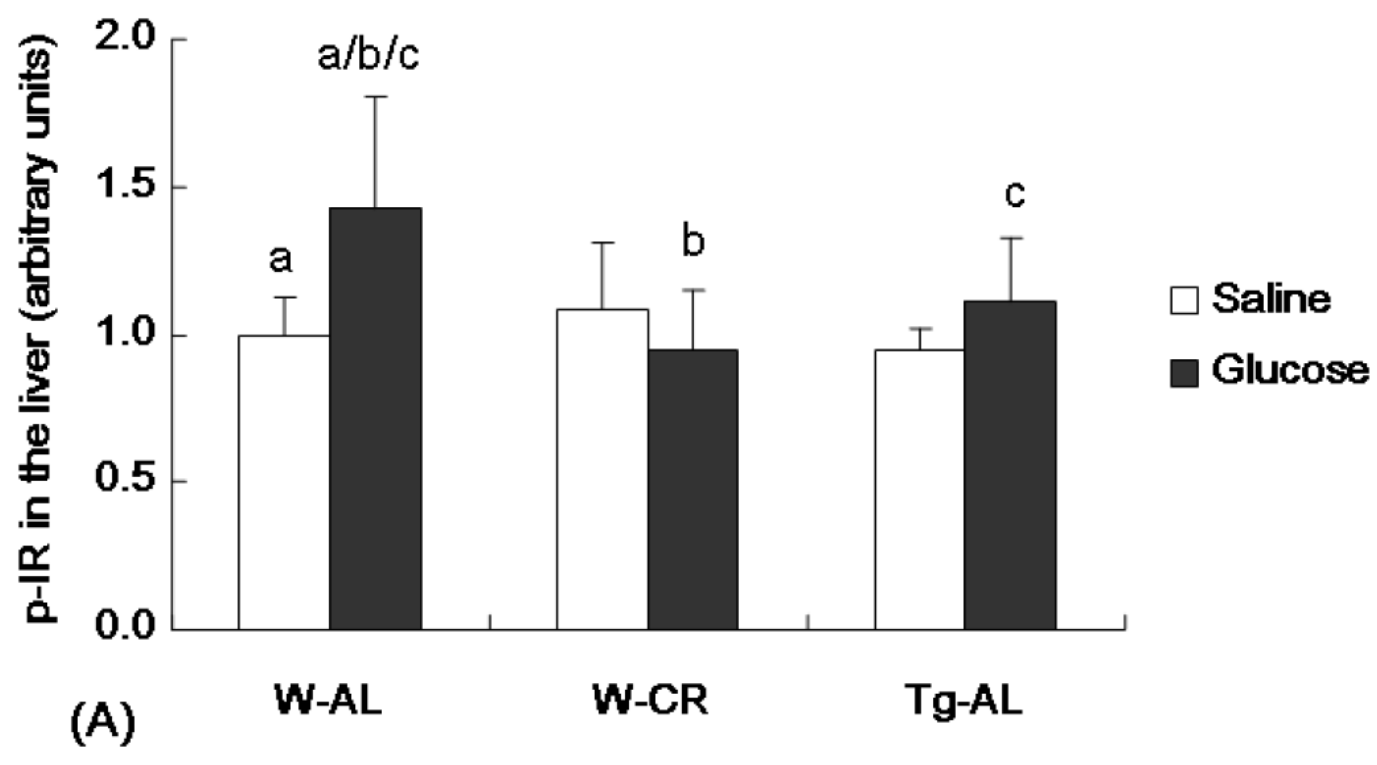

Fig 1B

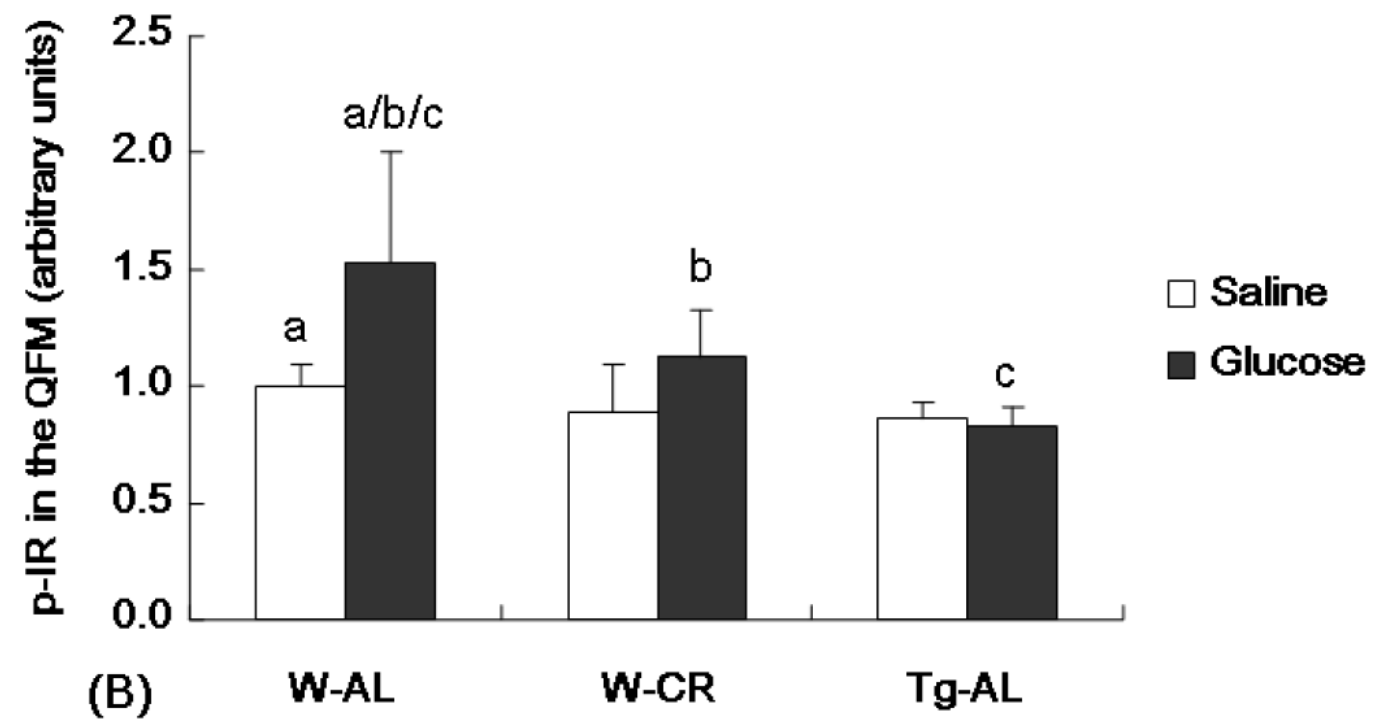


Fig 2A

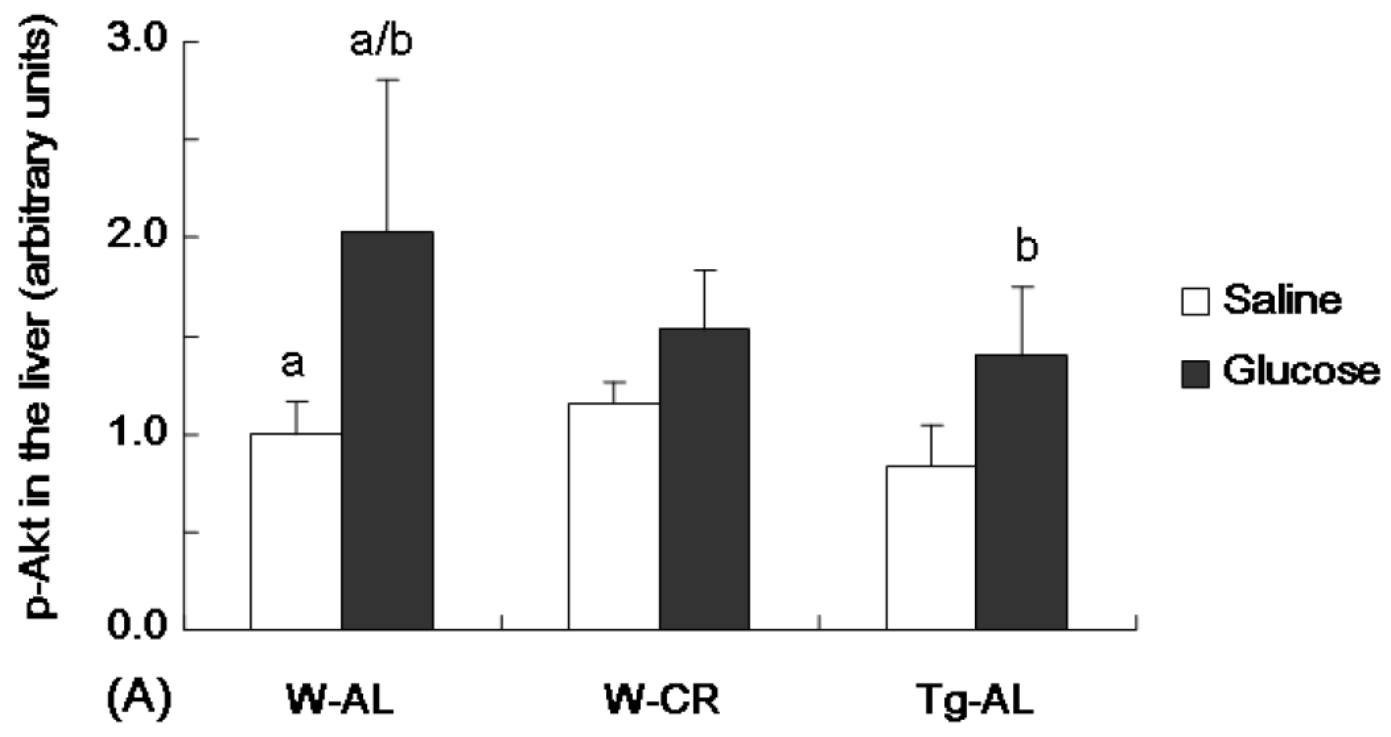

Fig 2B

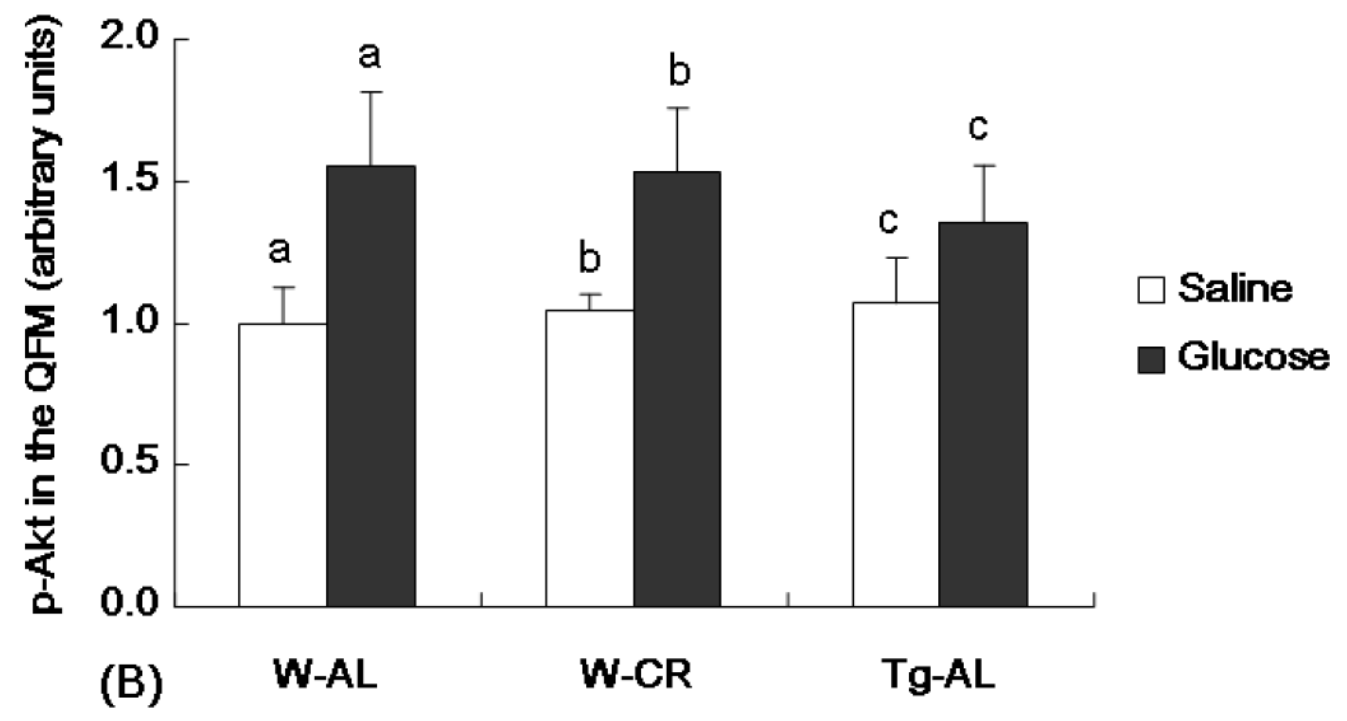


Fig 3A

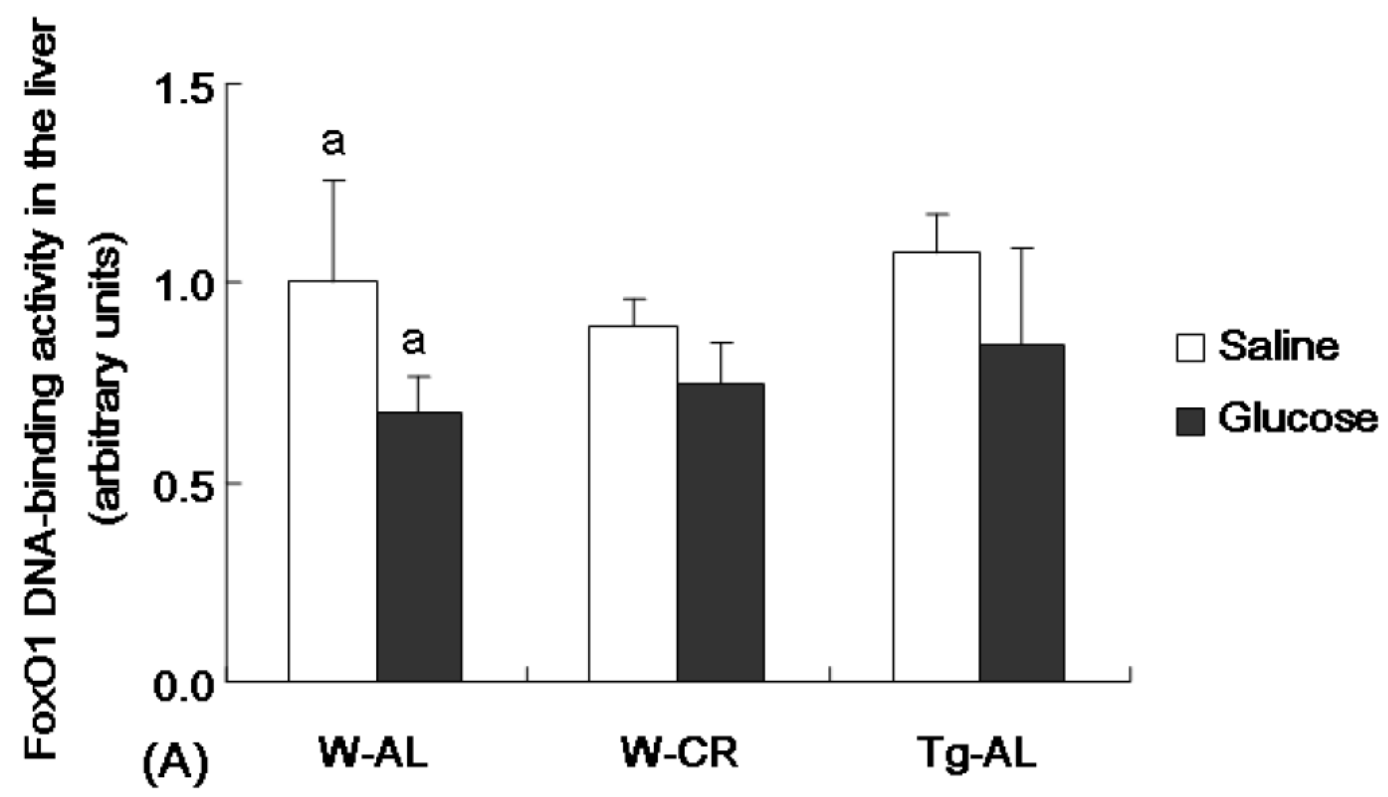

Fig 3B

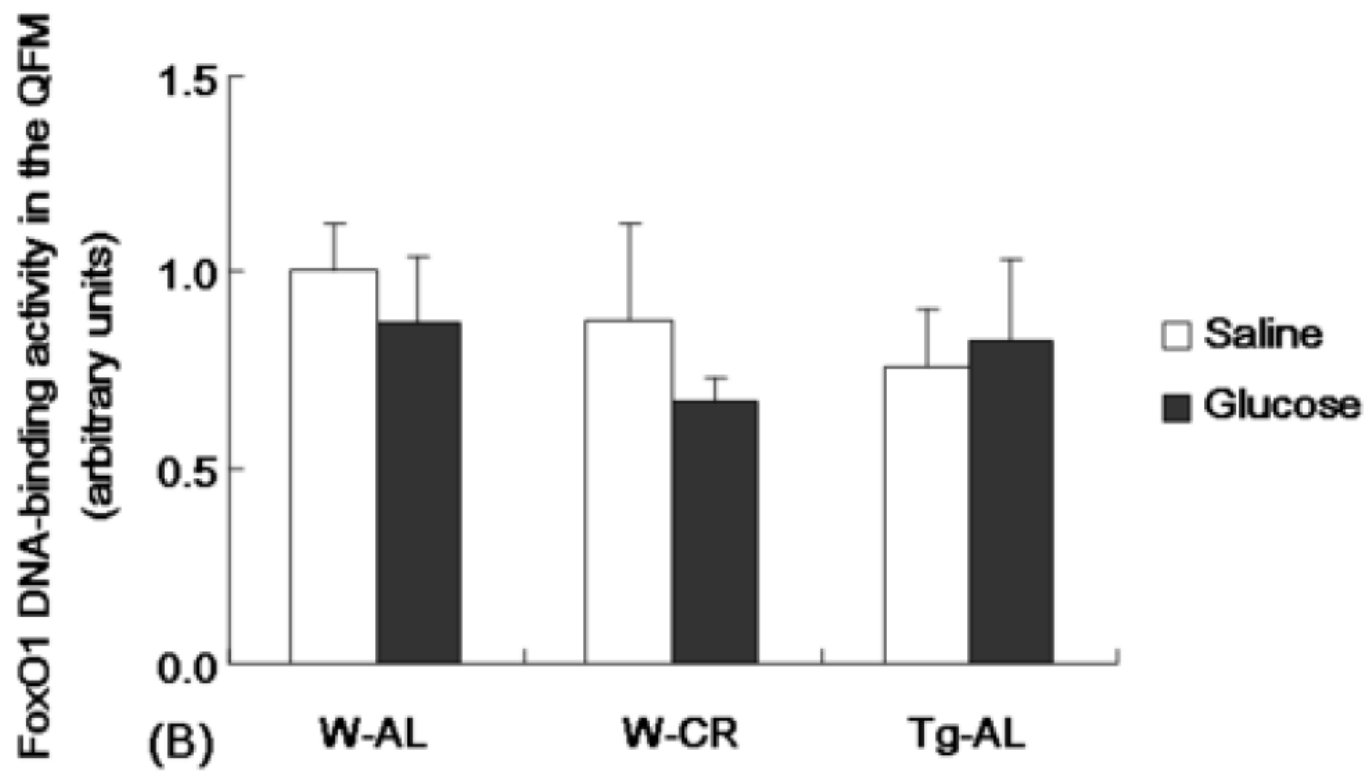




\section{Supplemental figure legend}

Figure 1. Levels of insulin receptor (IR) protein and phosphorylated IR in the liver (A, B) and quadriceps femoris muscles (QFM; C, D) from wild-type ad libitum-fed rats (W-AL), 30\% calorie-restricted rats (W-CR) and transgenic rats fed ad libitum (Tg-AL) detected by western blots. Each bar and line represent the mean $+\operatorname{SD}(n=4$ or 5$) .{ }^{*} \mathrm{p}<0.05$ versus (vs) saline in each rat group, \# $\mathrm{p}<0.05$ vs W-AL-glucose by 1 -f ANVOA with the post hoc test. Shared letters represent statistical differences at $\mathrm{p}<0.05$, determined by one-factor ANVOA with post hoc tests.

Figure 2. Levels of Akt protein and phosphorylated Akt in the liver (A, B) and quadriceps femoris muscles (QFM; C, D) from wild-type ad libitum-fed rats (W-AL), 30\% calorie-restricted rats $(\mathrm{W}-\mathrm{CR})$ and transgenic rats fed ad libitum (Tg-AL) detected by western blots. Each bar and

line represent the mean $+\mathrm{SD}(\mathrm{n}=4$ or 5$) .{ }^{*} \mathrm{p}<0.05$ versus (vs) saline in each rat group, $\# \mathrm{p}<0.05$ vs W-AL-glucose by 1-f ANVOA with the post hoc test. Shared letters represent statistical differences at $\mathrm{p}<0.05$, determined by one-factor ANVOA with post hoc tests.

\section{Supplemental methods}

Western blots of insulin receptor (IR) protein and phosphorylated IR

Frozen tissue from rat liver and QFM were homogenized in 10 volumes of ice-cold lysis buffer (50 mM Tris-HCl pH 7.4, 150 mM NaCl, 1\% Nonidet P-40, 1\% Triton X-100 1mM EDTA, 50 $\mathrm{mM} \mathrm{NaF}, 1 \mathrm{mM}$ sodium orthovanadate, $1 \mathrm{mM}$ PMSF, $5 \mathrm{ug} / \mathrm{ml}$ aprotinin) using a polytron homogenized for $30 \mathrm{sec}$ on ice. After $60 \mathrm{~min}$ incubation at $4^{\circ} \mathrm{C}$, insoluble material was removed by centrifugation at $20400 \mathrm{~g}$ for $20 \mathrm{~min}$ at $4^{\circ} \mathrm{C}$. Protein concentration of the supernatant was then measured by the Bradford method. Equal protein amounts $(8 \mathrm{mg})$ in $0.5 \mathrm{ml}$ lysis buffer were incubated with $2 \mu \mathrm{g}$ anti-insulin receptor $\beta$ subunit antibody (Santa Cruz Biotechnology, 
Santa Cruz, CA, USA) overnight at $4^{\circ} \mathrm{C}$ with constant agitation. Fifty micrograms protein A-Sepharose (50\% bead slurry, Amersham Pharmacia Biotech, Little Chalfont, UK) were added to the mixture and incubated with constant agitation at $4{ }^{\circ} \mathrm{C}$ for another $2 \mathrm{~h}$. The immunocomplex was then centrifuged at $20400 \mathrm{~g}$ for $30 \mathrm{sec}$ at $4{ }^{\circ} \mathrm{C}$ and the precipitate washed 4 times with ice-cold lysis buffer. Proteins were eluted by boiling for $10 \mathrm{~min}$ in $25 \mu \mathrm{l} 2 \mathrm{X}$ Laemmli SDS buffer and stored at $-80^{\circ} \mathrm{C}$ until needed for electrophoresis.

For western blotting, the immunocomplex sample was separated by SDS-PAGE and transferred to Immoblin P membrane (Millipore, Bedford, MA, USA). The membrane was incubated in a blocking buffer (Tris-buffered saline-Tween 20 (TBST) buffer (10 mM Tris-HCl $\mathrm{pH} 7.6,150 \mathrm{~mm} \mathrm{NaCl}$, and $0.1 \%$ Tween 20) containing $3 \% \mathrm{BSA}$ ) at $4^{\circ} \mathrm{C}$ overnight. After washing the membrane 3 times with TBST, the blot was incubated for $1 \mathrm{~h}$ at room temperature with anti-phosphotyrosine antibody (Santa Cruz Biotechnology) diluted in the blocking buffer, washed with TBST 3 times, incubated with anti-rabbit horseradish peroxidase-conjugated secondary antibody (Amersham Pharmacia Biotech), and washed 3 times with TBST. Signals were detected with ECL plus (Amersham Pharmacia Biotech).

For removing the antibodies, the membrane was incubated with Restore ${ }^{\mathrm{TM}}$ Western Blot Stripping Buffer (Pierce, Rockford, IL, USA) according to the manufacturer's instructions. Western blotting was performed using anti-insulin receptor $\beta$ subunit antibody with the same processes as described above.

Western blots of the Akt protein and phosphorylated Akt

Frozen tissues from rat liver and QFM were homogenized in 2 volumes of ice-cold STE buffer (20 mM Tris-HCl pH 7.5, 0.32 M sucrose 2 mM EDTA, 1 mM DTT, 100 mM NaF, 100 mM sodium pyrophosphate, $10 \mathrm{mM}$ sodium orthovanadate, $1 \mathrm{mM} \mathrm{PMSF}, 5 \mathrm{ug} / \mathrm{ml}$ aprotinin) using a polytron homogenizer for $30 \mathrm{sec}$ on ice. Homogenates were centrifuged at $1000 \mathrm{xg}$ for $25 \mathrm{~min}$ at $4^{\circ} \mathrm{C}$, and then the supernatant centrifuged at $100000 \mathrm{xg}$ for $1 \mathrm{~h}$ at $4^{\circ} \mathrm{C}$ to obtain the cytosolic fraction. Protein concentration of the supernatant was measured by the Bradford method. 
The same amounts of proteins $(40 \mu \mathrm{g})$ were subjected to SDS-PAGE and transferred to Immoblin P membrane. The blot was block with 5\% dry milk in TBST at $4^{\circ} \mathrm{C}$ overnight. After washing the membrane 3 times with TBST, the membrane was incubated for $1 \mathrm{~h}$ at room temperature with anti-phosoho Akt (Ser473) antibody (Cell Signaling Technology, Beverly, MA,USA) diluted in the blocking buffer, washed 3 times with TBST, incubated with anti-rabbit horseradish peroxidase-conjugated secondary antibody, and washed 3 times with TBST. Signals were detected with ECL plus.

After stripping the antibodies with Restore ${ }^{\mathrm{TM}}$ Western Blot Stripping Buffer, western blotting was performed using the anti-Akt antibody (Santa Cruz Biotechnology). 


\section{Comments on supplemental table 1}

The TG concentration was slightly lower in W-CR rats compared with W-AL rats, particularly in the glucose-injected groups. There was no statistical difference between $\mathrm{W}$-CR and $\mathrm{Tg}-\mathrm{AL}$ rats or between $\mathrm{W}-\mathrm{AL}$ and $\mathrm{Tg}-\mathrm{AL}$ rats.

The total cholesterol levels did not differ significantly between the three rat groups, although the glucose-injected groups showed slightly higher levels compared with the saline-injected groups.

The HDL-cholesterol level was greater in W-CR rats than in W-AL rats, particularly after glucose injection. The levels were significantly greater in Tg-AL rats than in W-AL rats in both the saline- and glucose-injected groups. There was no difference between $\mathrm{W}-\mathrm{CR}$ and $\mathrm{Tg}-\mathrm{AL}$ rats. In contrast, LDL-cholesterol levels in W-CR and Tg-AL rats were lower, particularly in saline-injected groups. There was no difference between the $\mathrm{W}-\mathrm{CR}$ and $\mathrm{Tg}-\mathrm{AL}$ groups.

The FFA level was lower in the glucose-injected groups than in saline-injected groups in all rat groups. The levels were high in Tg-AL rats as compared to W-CR rats. The FFA level in glucose-injected Tg-AL rats was also slightly higher compared with the W-AL rats.

The HB levels were significantly lower in glucose-injected groups than in saline-injected groups. The levels did not differ significantly between the three rat groups, except between $\mathrm{W}-\mathrm{CR}$ and $\mathrm{Tg}-\mathrm{AL}$ rats after glucose injection. 


\section{Table 1}

Supplemental Table 1. Blood lipid levels

\begin{tabular}{lcccccc}
\hline & \multicolumn{2}{c}{ W-AL } & \multicolumn{2}{c}{ W-CR } & \multicolumn{2}{c}{ Tg-AL } \\
\hline & Saline & Glucose & Saline & Glucose & Saline & Glucose \\
\hline Triacylglycerol & $138.4 \pm 30.9$ & $165.0 \pm 46.4^{\mathrm{a}}$ & $98.4 \pm 46.0$ & $91.2 \pm 43.3^{\mathrm{a}}$ & $111.5 \pm 49.3$ & $112.3 \pm 41.5$ \\
Total cholesterol & $85.2 \pm 18.0^{\mathrm{a}}$ & $103.4 \pm 21.3^{\mathrm{a}}$ & $78.2 \pm 10.0$ & $95.0 \pm 8.6$ & $95.0 \pm 6.2$ & $104.4 \pm 8.6$ \\
HDL-cholesterol & $23.4 \pm 3.8^{\mathrm{b}}$ & $26.4 \pm 4.0^{\mathrm{c} / \mathrm{d}}$ & $27.2 \pm 3.3^{\mathrm{a}}$ & $31.8 \pm 1.5^{\mathrm{a} / \mathrm{c}}$ & $31.8 \pm 2.6^{\mathrm{b}}$ & $32.2 \pm 3.6^{\mathrm{d}}$ \\
LDL-cholesterol & $10.2 \pm 2.8^{\mathrm{a} / \mathrm{b}}$ & $9.4 \pm 3.1$ & $7.6 \pm 1.1^{\mathrm{a}}$ & $9.4 \pm 1.1$ & $7.3 \pm 1.0^{\mathrm{b}}$ & $9.2 \pm 0.4$ \\
Free fatty acids & $1.34 \pm 0.12^{\mathrm{a}}$ & $1.00 \pm 0.14^{\mathrm{a} / \mathrm{e}}$ & $1.31 \pm 0.24^{\mathrm{b} / \mathrm{d}}$ & $0.97 \pm 0.35^{\mathrm{b} / \mathrm{f}}$ & $1.64 \pm 0.16^{\mathrm{c} / \mathrm{d}}$ & $1.32 \pm 0.21^{\mathrm{c} / / / \mathrm{s}}$ \\
D-3-Hydrobutyrate & $1256 \pm 165^{\mathrm{a}}$ & $382 \pm 89^{\mathrm{a}}$ & $1073 \pm 216^{\mathrm{b}}$ & $196 \pm 59^{\mathrm{b} / \mathrm{d}}$ & $1124 \pm 227^{\mathrm{c}}$ & $599 \pm 297^{\mathrm{c} / \mathrm{d}}$ \\
\hline
\end{tabular}

Notes: Data represent the mean $\pm \mathrm{SD}(\mathrm{mg} / \mathrm{dL}: \mathrm{n}=5$ for each treatment in $\mathrm{W}$-AL and $\mathrm{W}-\mathrm{CR}$ groups; $\mathrm{n}=4$ for each treatment in Tg-AL group). Shared letters indicate statistical difference, $\mathrm{p}<0.05$, by 1 -f ANOVA with the post hoc test. W-AL, wild-type ad libitum-fed rats; $\mathrm{W}-\mathrm{CR}, 30 \%$ calorie-restricted rats; $\mathrm{Tg}-\mathrm{AL}$, transgenic rats fed ad libitum. 
Supplemental Fig 1A
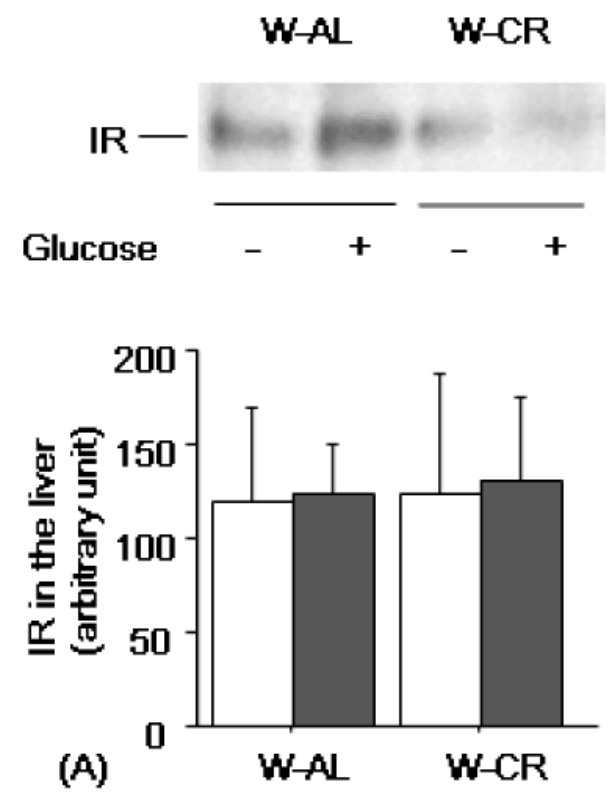

\section{Saline}

Glucose

Supplemental Fig 1B
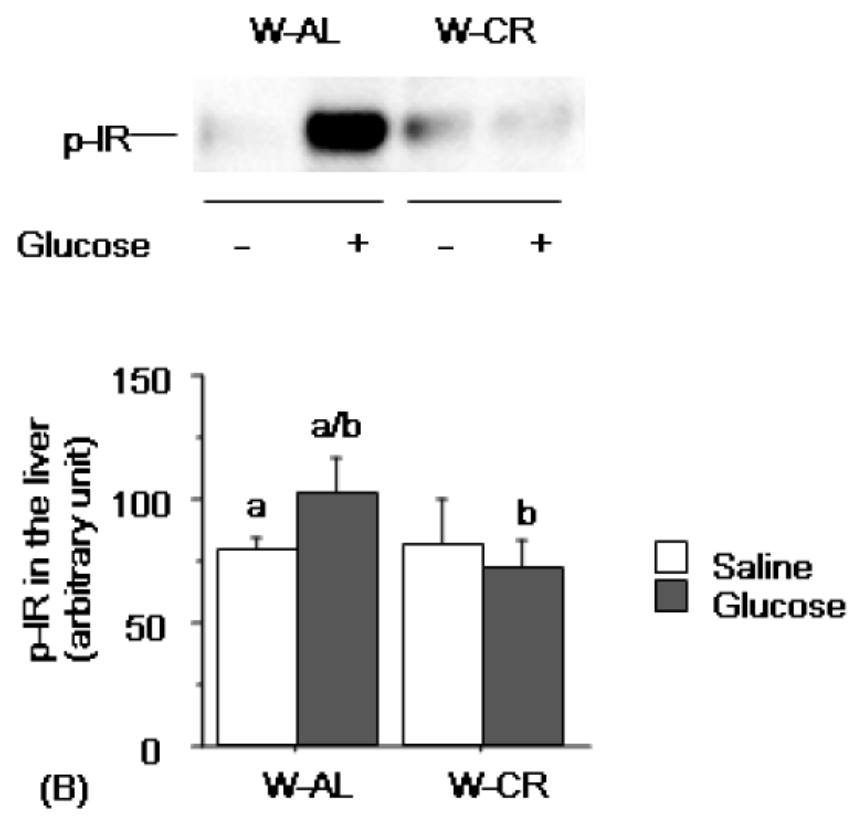
Supplemental Fig 1C
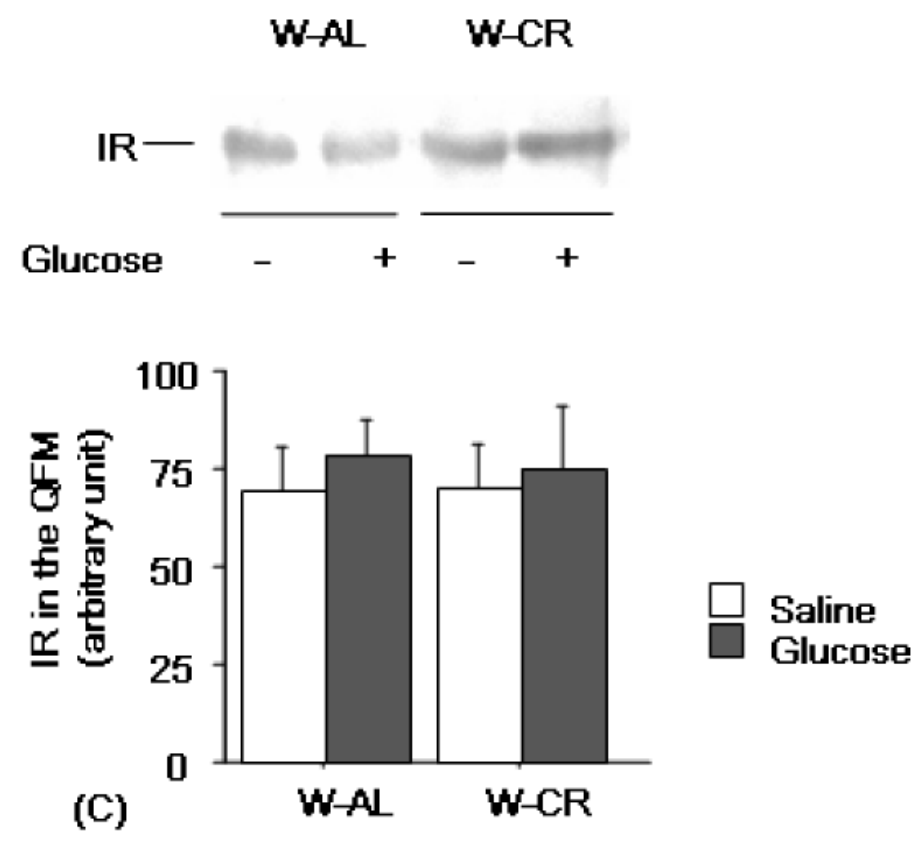

Supplemental Fig 1D
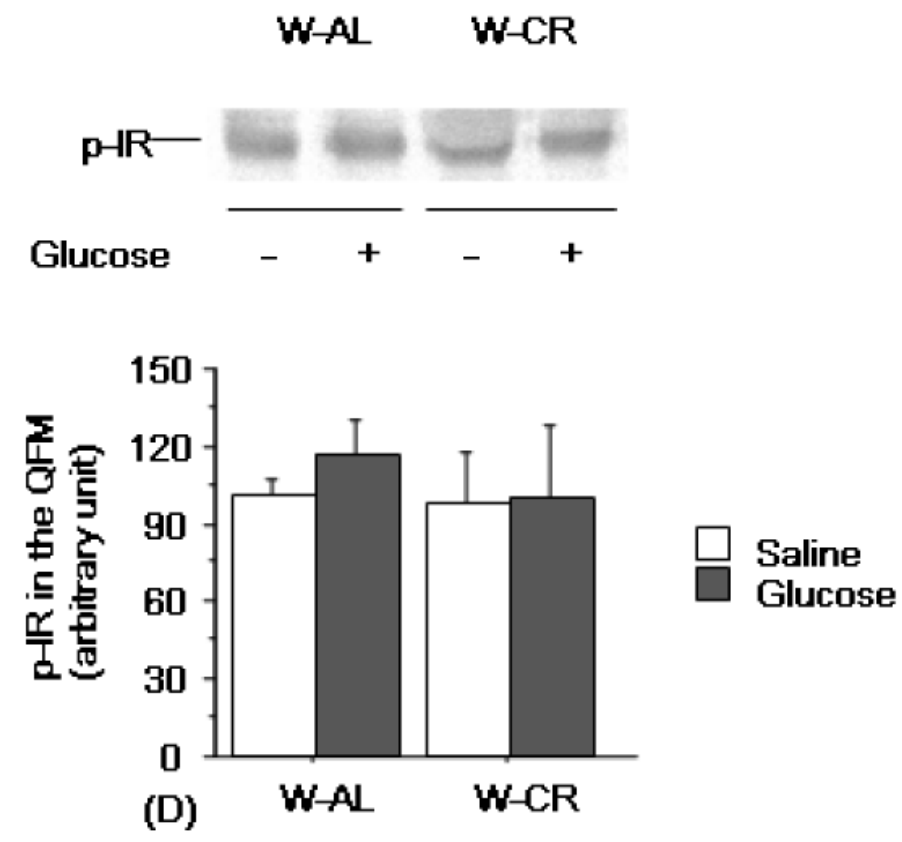
Supplemental Fig 2A
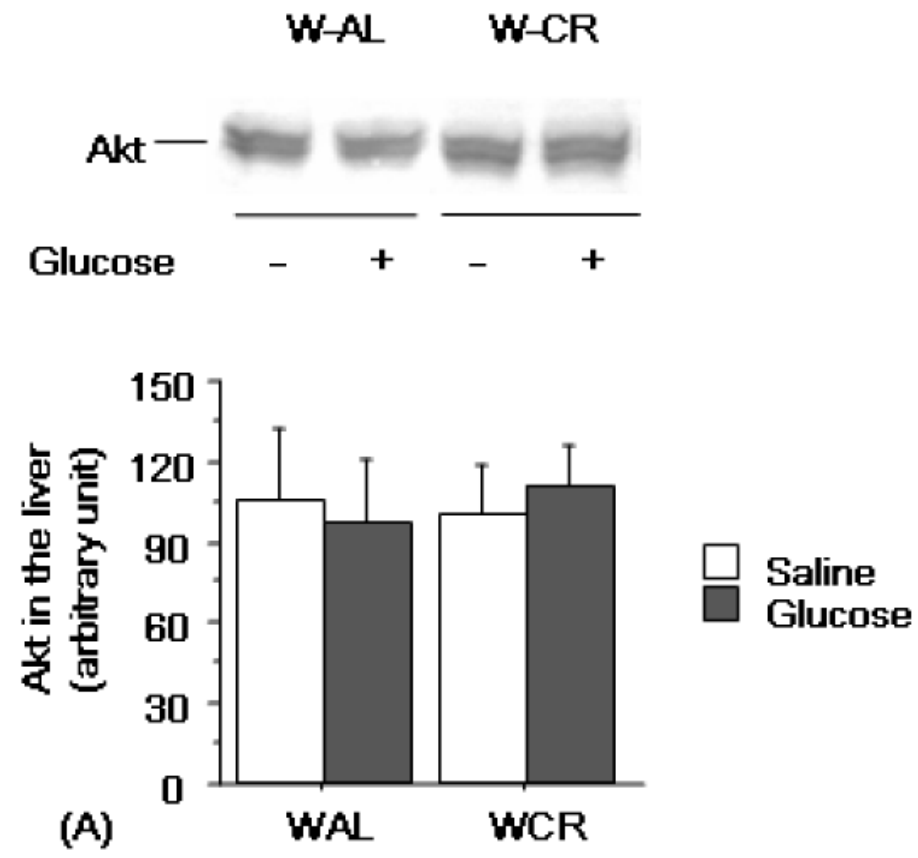

Supplemental Fig 2B

W-AL W-CR
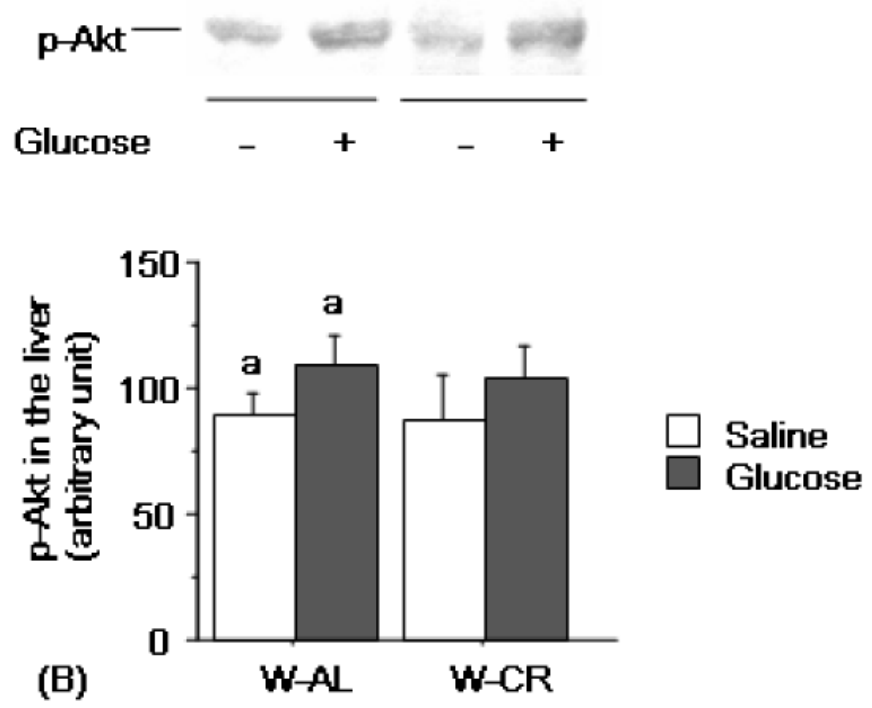
Supplemental Fig 2C
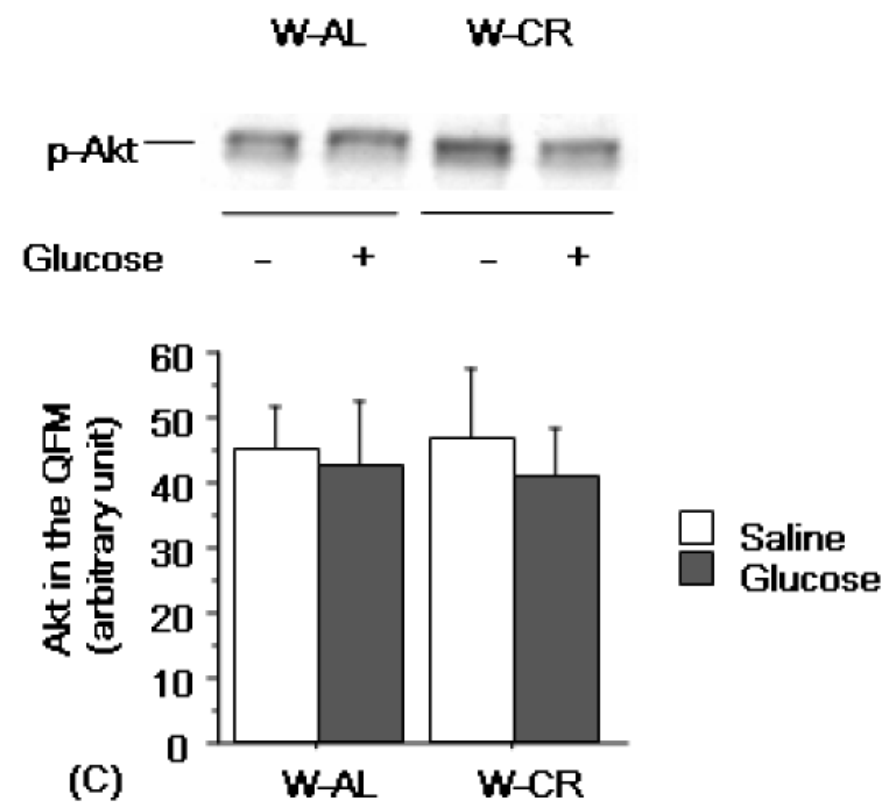

Supplemental Fig 2D

W-AL W-CR
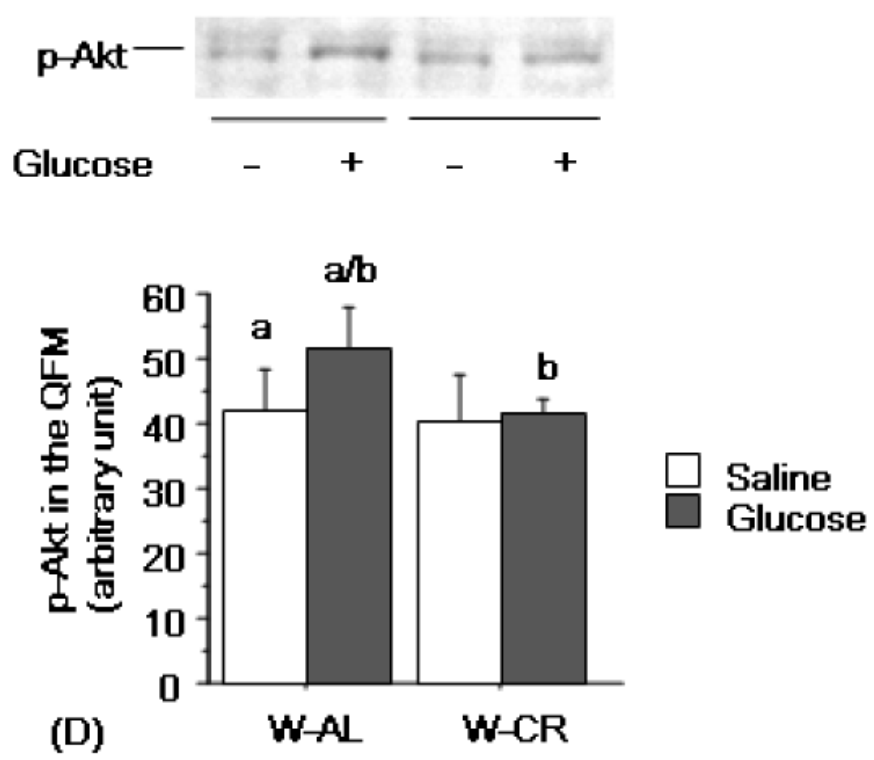